\title{
Vitrectomy for Proliferative Diabetic Retinopathy in a Patient with Heparin-Induced Thrombocytopenia
}

\author{
Tomoko Fujii $^{a}$ Mari Akashi ${ }^{a}$ Seita Morishita ${ }^{a}$ Masanori Fukumoto ${ }^{a}$

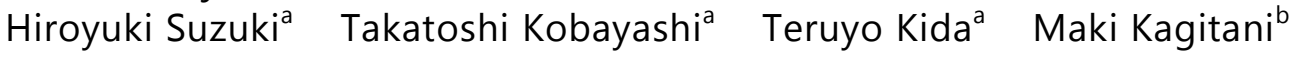 \\ Ichiro Morino $^{c}$ Tsunehiko Ikeda ${ }^{a}$ \\ ${ }^{a}$ Department of Ophthalmology, and ${ }^{b}$ Blood Purification Center, Osaka Medical College, \\ Takatsuki City, and ${ }^{C}$ Morino Eye Clinic, Osaka City, Japan
}

\section{Key Words}

Proliferative diabetic retinopathy · Vitrectomy · Heparin-induced thrombocytopenia ·

Argatroban hydrate

\begin{abstract}
Introduction: In this study, we report a case of proliferative diabetic retinopathy in a patient with heparin-induced thrombocytopenia (HIT) in whom vitrectomy was performed with good results. Case: A 57-year-old man presented with a chief complaint of decreased visual acuity (VA) in the left eye. Corrected VA of the left eye was 0.03 , and ophthalmic examination showed fibrovascular membranes along the vascular arcade and a combined rhegmatogenous-traction retinal detachment with a macular hole. The patient began hemodialysis for diabetic nephropathy in March 2014; thrombocytopenia developed after dialysis was started, and HIT was diagnosed after further evaluation. Argatroban hydrate was being used during dialysis. Treatment was switched from warfarin to argatroban hydrate 6 days prior to vitrectomy being performed on the patient's left eye. Although there was bleeding with somewhat difficult hemostasis during the intraoperative treatment of the fibrovascular membranes, surgery was completed without complications and the postoperative course was good. Discussion: Vitrectomy was performed with good results in this patient with HIT. Treatment with argatroban hydrate during surgery enabled surgery without the danger of intraoperative clotting.


Fujii et al.: Vitrectomy for Proliferative Diabetic Retinopathy in a Patient with HeparinInduced Thrombocytopenia

\section{Introduction}

Heparin-induced thrombocytopenia (HIT) is a serious adverse effect of heparin caused by platelet-activating antibodies $[1,2]$. HIT is a paradoxical prothrombotic disorder in which thrombosis is caused by an anticoagulant. The incidence rate of HIT varies depending on the underlying disorder, but it generally affects $0.5-5 \%$ of patients treated with heparin [3]. Precautions are required when surgery is performed in patients with HIT, and we have found no previous reports of vitrectomy in a HIT patient. In this present study, we report the case of a patient with HIT in whom vitrectomy was performed for proliferative diabetic retinopathy (PDR).

\section{Case History}

A 57-year-old male presented with the chief complaint of bilateral decreased visual acuity (VA). He had previously undergone hemodialysis for diabetic nephropathy in March 2014, and after starting hemodialysis, thrombocytopenia was noted, blood clots were found in the hemodialysis circuit, and further evaluation showed elevated anti-HIT antibody levels, thus leading to a diagnosis of HIT. He also had hepatitis $\mathrm{C}$ and hypertension. The family medical history was unremarkable.

\section{Case Report}

The patient had been treated by a local physician for diabetic retinopathy since 2007, and photocoagulation of both retinas was performed in 2011. The patient had not been examined for 1 year after 2013, and PDR had progressed in both eyes by early 2014. He was subsequently referred to the Department of Ophthalmology, Osaka Medical College Hospital, for surgery on his left eye in March 2014.

\section{Findings upon Initial Evaluation}

Upon initial examination, the patient's VA was $0.4\left(1.0 \times \mathrm{S}+1.0 \mathrm{D}=\mathrm{C}-1.75 \mathrm{~A} \times 90^{\circ}\right)$ in his right eye and 0.03 (uncorrectable) in his left eye. Intraocular pressure was $14 \mathrm{~mm} \mathrm{Hg}$ in his right eye and $13 \mathrm{~mm} \mathrm{Hg}$ in his left eye. The patient had an intraocular lens in both eyes. The examination of the anterior eye and optic media was unremarkable. Bilateral fundi showed proliferative fibrovascular membranes along the vascular arcades. In his right eye, there was traction retinal detachment inferiorly and vitreous hemorrhage. In his left eye, there was traction retinal detachment extending superiorly from the macula and a macular hole (fig. 1). Blood tests indicated poorly controlled diabetes with an HbA1c of 9.3\%.

\section{Treatment Course}

In the patient's left eye, vitrectomy using a 25-gauge system, removal of the fibrovascular membranes, retinal photocoagulation, and gas tamponade with $20 \% \mathrm{SF}_{6}$ were performed. Mild bleeding during the removal of the fibrovascular membranes was noted, yet the surgery was successfully completed. Postoperatively, the corrected VA of the patient's left eye was 0.09. Residual subretinal fluid was gradually decreased and the macular hole was closed (fig. 2).

Perioperative anticoagulation was managed in consultation with the Blood Purification Center at our hospital. His body weight was $63.45 \mathrm{~kg}$ on admission. Immediately, warfarin 
Fujii et al.: Vitrectomy for Proliferative Diabetic Retinopathy in a Patient with HeparinInduced Thrombocytopenia

was stopped, and because heparin could not be used, argatroban hydrate (0.2-0.7 $\mu \mathrm{g} / \mathrm{min} / \mathrm{kg}$ ) alone was used for anticoagulation. The dose of argatroban hydrate was increased to $240 \mathrm{mg}$ /day on day 3 after warfarin was stopped. Blood tests were done daily to control the activated partial thromboplastin time to about $50 \mathrm{~s}$. The patient also received argatroban hydrate by continuous i.v. infusion during the surgery.

On the day after surgery, warfarin ( $3 \mathrm{mg} /$ day) was resumed while continuing on argatroban hydrate $(170 \mathrm{mg} /$ day). After his discharge from the hospital, the anticoagulation was managed with warfarin (3 mg/day) alone (fig. 3). Finally, prothrombin timeinternational normalized ratio has been controlled around 2.5 .

\section{Discussion}

First introduced in the 1950s, heparin has been used for more than 60 years (e.g., during cardiovascular surgery), and is an essential drug for the treatment of thromboembolism in the perioperative period. However, heparin can also cause thrombocytopenia by an immunologic mechanism. Thus, the concept of HIT was proposed as a disorder in which thromboembolism rather than bleeding can develop [1, 2]. In 1992, antibodies that recognize the heparin-platelet factor 4 complex were reported as the cause of HIT [4, 5].

HIT is classified as either type I or type II based on the mechanism of development [6, 7]. HIT type I develops soon after heparin is started (i.e., 2-3 days) due to a direct effect of heparin on platelet aggregation; thrombocytopenia is mild, and heparin can usually be continued. HIT type II is more severe and requires treatment. The mechanism involves platelet activation by heparin and platelet factor 4 binding to heparin to form an immune complex. This complex binds to and crosslinks platelet receptors, leading to strong platelet activation and platelet aggregation.

The incidence rate of HIT varies depending on the underlying disease, but it generally affects $0.5-5 \%$ of patients who receive heparin [3]. The incidence of complications such as thrombosis is $25-50 \%$ if HIT is not treated, with a mortality rate of approximately $5 \%$. Specific events that may predispose patients to HIT are those in which heparin is used, including coronary artery bypass graft surgery and when starting hemodialysis. HIT is most common in Western countries where unfractionated heparin is used to prevent thrombosis after orthopedic surgery. The diagnosis of HIT is based on a combination of detection of HIT antibodies and the following 4 clinical findings: (1) severity of thrombocytopenia, (2) time of platelet reduction, (3) presence of thrombosis, and (4) possibilities other than HIT.

However, since antibody testing can take a long time, in actual clinical practice, a platelet count $\leq 50 \%$ of the original platelet count or $\leq 100,000 / \mu l$, together with symptoms, suggests HIT, and treatment should be initiated. Treatment involves discontinuing to use heparin and usually initiating argatroban, an antithrombin drug [8-10]. Reports of ophthalmic complications in HIT patients include orbital hematomas [11] and retinal vein occlusion [12], but the number of reported cases is very small. In fact, we found no previous reports of ophthalmic surgery in HIT patients. In the present patient, switching from warfarin to argatroban before vitrectomy enabled vitrectomy to be performed safely without any systemic adverse events.

Patients with PDR who also have renal dysfunction often tend to develop clots during vitrectomy, but despite renal dysfunction in the present patient, the intraoperative administration of argatroban hydrate allowed for successful completion of the vitrectomy without the danger of clotting. Thus, these findings show that intravenous argatroban hydrate can be used prophylactically to easily prevent clotting during vitrectomy in the clinical setting. The drugs half-life is $30 \mathrm{~min}$, and it has an anticoagulant effect for about $15 \mathrm{~min}$ after administra- 
Fujii et al.: Vitrectomy for Proliferative Diabetic Retinopathy in a Patient with HeparinInduced Thrombocytopenia

tion. Therefore, by stopping argatroban as soon as the dissection of the fibrovascular membranes is completed, there is little risk of postoperative bleeding and clotting can be safely controlled [13]. A worsening of PDR with increased platelet aggregation has also been reported $[14,15]$. Hence, although HIT activity is suppressed by anticoagulant drugs, careful follow-up is required to observe whether or not PDR is worsened by HIT.

\section{Acknowledgements}

The authors wish to thank John Bush for editing the manuscript.

\section{Statement of Ethics}

This study was approved by the Ethics Committee of Osaka Medical College, Takatsuki City, Osaka, Japan.

\section{Disclosure Statement}

The authors have no conflicts of interest to report.

\section{References}

1 Gollub S, Ulin AW: Heparin-induced thrombocytopenia in man. J Lab Clin Med 1962;59:430-435.

-2 Natelson EA, Lynch EC, Alfrey CP Jr, Gross JB: Heparin-induced thrombocytopenia. An unexpected response to treatment of consumption coagulopathy. Ann Intern Med 1969;71:1121-1125.

-3 Salzman EW, Rosenberg RD, Smith MH, Lindon JN, Favreau L: Effect of heparin and heparin fractions on platelet aggregation. J Clin Invest 1980;65:64-73.

-4 Amiral J, Bridey F, Dreyfus M, Vissoc AM, Fressinaud E, Wolf M, Meyer D: Platelet factor 4 complexed to heparin is the target for antibodies generated in heparin-induced thrombocytopenia. Thromb Haemost 1992;68:95-96.

5 Visentin GP: Heparin-induced thrombocytopenia: molecular pathogenesis. Thromb Haemost 1999;82:448456.

6 Greinacher A, Alban S, Dummel V, Franz G, Mueller-Eckhardt C: Characterization of the structural requirements for a carbohydrate based anticoagulant with a reduced risk of inducing the immunological type of heparin-associated thrombocytopenia. Thromb Haemost 1995;74:886-892.

7 Gupta AK, Kovacs MJ, Sauder DN: Heparin-induced thrombocytopenia. Ann Pharmacother 1998;32:55-59.

-8 Lewis BE, Wallis DE, Leya F, Hursting MJ, Kelton JG: Argatroban anticoagulation in patients with heparininduced thrombocytopenia. Arch Intern Med 2003;163:1849-1856.

-9 Lewis BE, Wallis DE, Berkowitz SD, Matthai WH, Fareed J, Walenga JM, Bartholomew J, Sham R, Lerner RG, Zeigler ZR, Rustagi PK, Jang IK, Rifkin SD, Moran J, Hursting MJ, Kelton JG; ARG-911 Study Investigators: Argatroban anticoagulant therapy in patients with heparin-induced thrombocytopenia. Circulation 2001;103:1838-1843.

10 Matsuo T, Kario K, Chikahira Y, Nakao K, Yamada T: Treatment of heparin-induced thrombocytopenia by use of argatroban, a synthetic thrombin inhibitor. Br J Haematol 1992;82:627-629.

-11 Mansurali N, Maclaren G, Sundar G: Bilateral orbital haematomas in an anticoagulated patient with severe H1N1 influenza. Orbit 2011;30:98-100.

12 Nguyen QD, Van Do D, Feke GT, Demirjian ZN, Lashkari K: Heparin-induced antiheparin-platelet antibody associated with retinal venous thrombosis. Ophthalmology 2003;110:600-603.

13 Maeno T, Tano Y, Mano T, Takenaka H: Argatroban inhibits intraocular fibrin formation after vitrectomy in rabbits. Arch Ophthalmol 2000;118:1401-1405.

14 Creter D, Pavlotzky F, Savir H: Platelet aggregation in diabetic retinopathy. Acta Haematol 1978;60:53-55. Ho PC, Feman SS, Stein RS, McKee LC: Proliferative diabetic retinopathy in patients with defects of platelet function. Am J Ophthalmol 1979;88:37-39. 


\section{Case Reports in \\ Ophthalmology}

Case Rep Ophthalmol 2016;7:67-73

DOI: $10.1159 / 000443720$ (C) 2016 The Author(s). Published by S. Karger AG, Basel www.karger.com/cop

Fujii et al.: Vitrectomy for Proliferative Diabetic Retinopathy in a Patient with Heparin Induced Thrombocytopenia
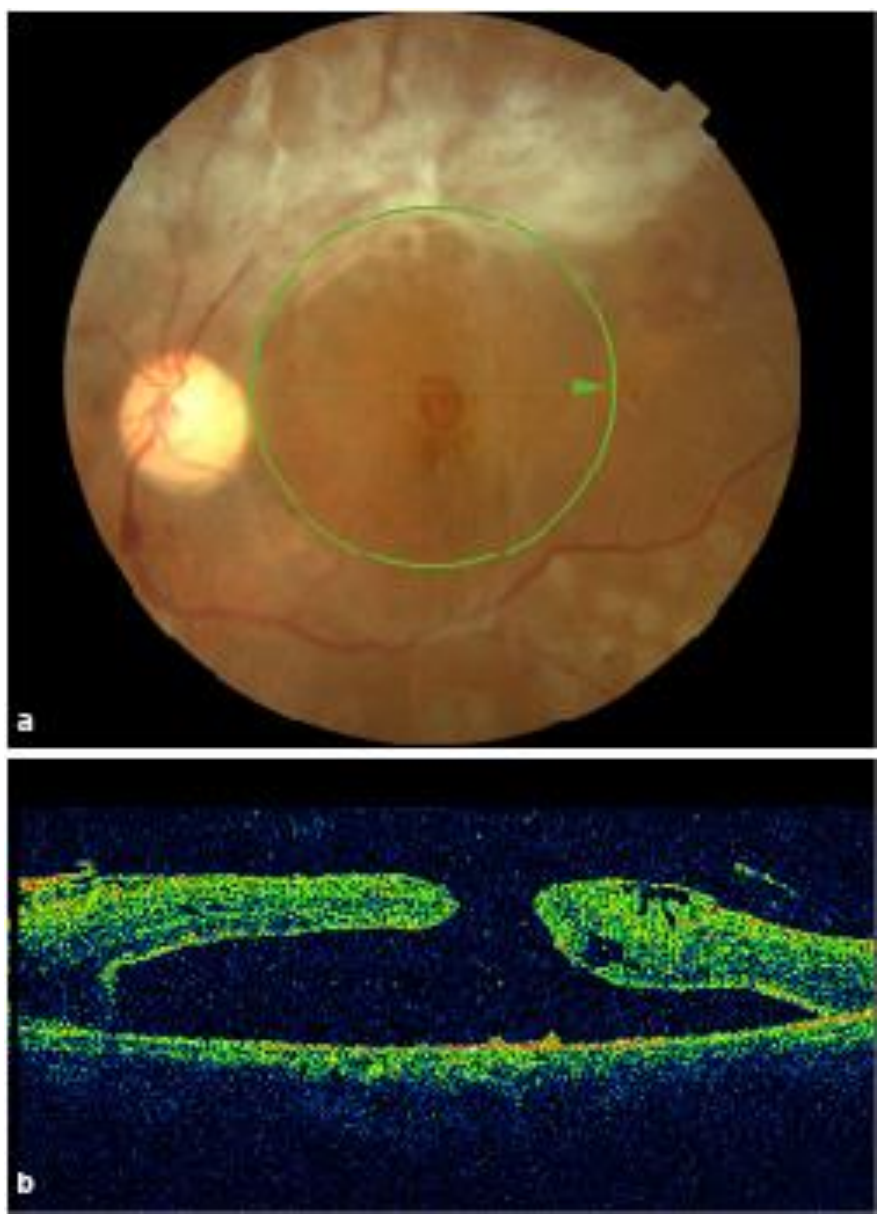

Fig. 1. Preoperative fundus findings of the patient's left eye. a Fundus image showing that the proliferative fibrovascular membranes are present superiorly along the vascular arcade. b Optical coherence tomography image showing that macular traction is present superiorly, with formation of a macular hole. 


\section{Case Reports in \\ Ophthalmology}

\begin{tabular}{l|l}
\hline Case Rep Ophthalmol 2016;7:67-73 \\
\hline DOI: 10.1159/000443720 & $\begin{array}{l}\text { ○ } 2016 \text { The Author(s). Published by S. Karger AG, Basel } \\
\text { www.karger.com/cop }\end{array}$
\end{tabular}

Fujii et al.: Vitrectomy for Proliferative Diabetic Retinopathy in a Patient with HeparinInduced Thrombocytopenia

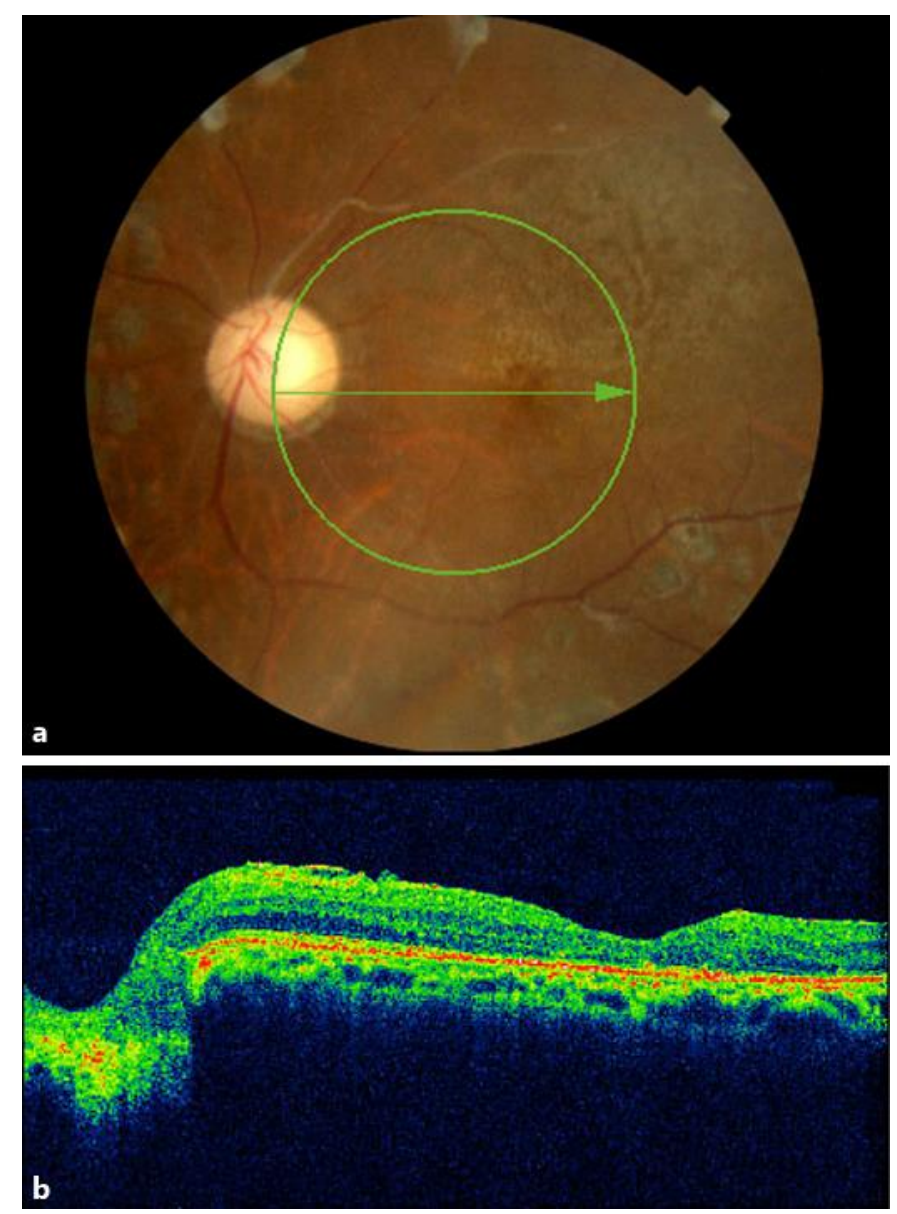

Fig. 2. Postoperative fundus findings of the patient's left eye. a Fundus image showing that the proliferative fibrovascular membranes are removed and that the retina is reattached. $\mathbf{b}$ Optical coherence tomography image showing that residual subretinal fluid had gradually decreased and that the macular hole was closed. 
Case Reports in

Ophthalmology
Case Rep Ophthalmol 2016;7:67-73

\begin{tabular}{l|l}
\hline DOI: $10.1159 / 000443720$ & C 2016 The Author(s). Published by S. Karger AG, Basel
\end{tabular} www.karger.com/cop

Fujii et al.: Vitrectomy for Proliferative Diabetic Retinopathy in a Patient with HeparinInduced Thrombocytopenia

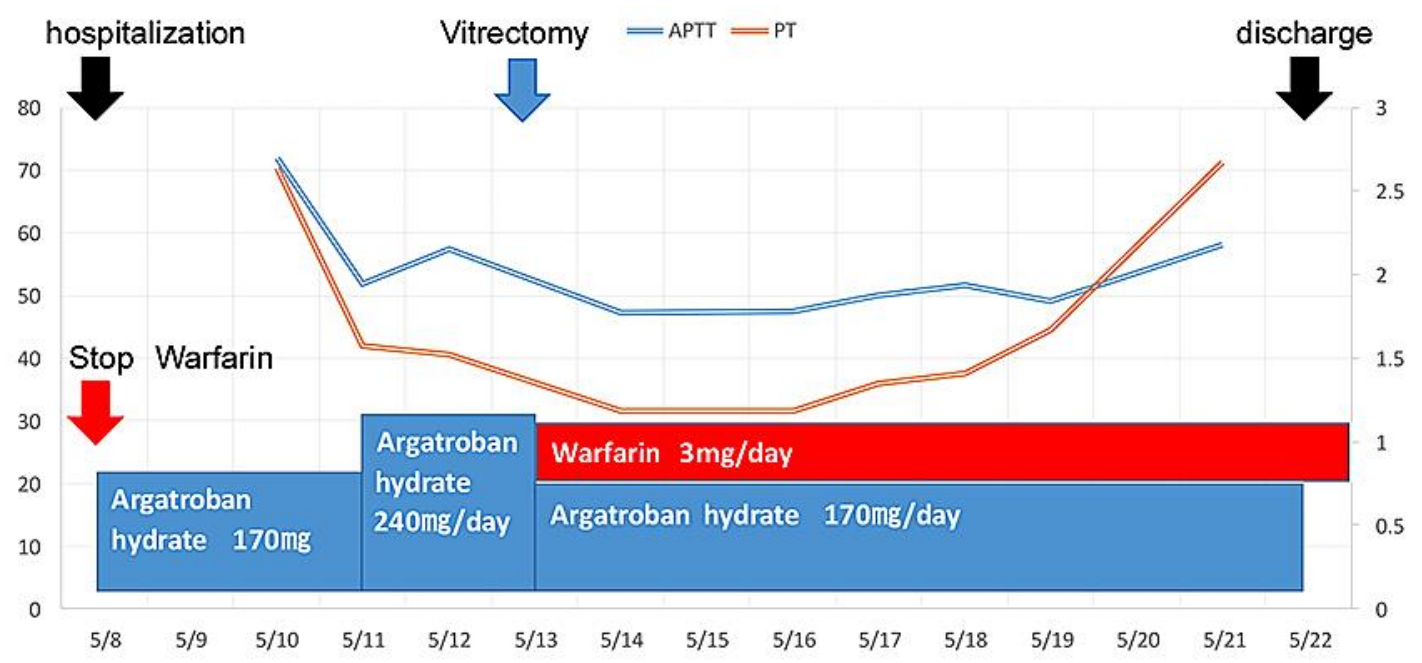

※Hemodialysis $3 /$ week

Fig. 3. Graph illustrating the treatment course of the patient from hospitalization to discharge. APTT = Activated partial thromboplastin time; $\mathrm{PT}=$ prothrombin time. 